\title{
AVALIAÇÃO DA SOBREVIVÊNCIA DE BRADYRHIZOBIUM SPP EM SEMENTES DE SOJA TRATADAS COM FUNGICIDAS, PROTETOR CELULAR E INOCULANTE
}

\section{EVALUATION OF SURVIVAL BRADYRHIZOBIUM SPP IN SOYBEAN SEED TREATED WITH FUNGICIDES, GUARD AND CELLULAR INOCULANT}

\author{
Bettina Berquó Marks \\ bettinamarks@gmail.com \\ Universidade Estadual de Londrina - UEL \\ Eliane Villamil Bangel \\ elianebangel@gmail.com \\ Laboratório de Microbiologia Agrícola - FEPAGRO \\ Vanessa Tedesco \\ vavatedesco@yahoo.com.br \\ Sabrina Letícia Couto da Silva \\ sassalelenash@yahoo.com.br \\ Silviane Barra Ferreira \\ silvibarraferrreira@bol.com.br \\ Laboratório de Microbiologia Agrícola - FEPAGRO \\ Rafael Vargas \\ Laboratório de Microbiologia Agrícola - FEPAGRO \\ Gilmário Marques Silva \\ Laboratório de Microbiologia Agrícola - FEPAGRO
}

\section{RESUMO}

A aplicação de técnicas agrícolas modernas tem papel importante na manutenção do patamar de segundo maior produtor e exportador de soja alcançado pelo Brasil. Entre essas técnicas destacamse a inoculação com bradirrizóbios e o tratamento de sementes com fungicidas. Estudos já realizados demonstraram incompatibilidade entre as bactérias inoculadas com as demais práticas de tratamento de sementes. Em função disso, algumas indústrias elaboraram aditivos celulares, que favorecem a sobrevivência de microorganismos inoculados nas sementes, mesmo em presença de fungicidas. Esse estudo teve como objetivo avaliar o efeito de um aditivo celular na sobrevivência de bradirrizóbios em sementes de soja inoculadas e tratadas com diferentes fungicidas. $O$ ensaio foi

Revista Internacional de Ciências · v.3 - n.1 · jan./jun. 2013

Trabalho apresentado no XXXIII Congresso Brasileiro de Ciência do Solo (2009) e com financiamento da Merck Crop Bioscience Argentina S/A. 
conduzido em 2008 no Laboratório de Microbiológica Agrícola (MIA) da FEPAGRO. Sementes de soja foram tratadas com quatro fungicidas comerciais (Protreat, Vitavax-Thiram, Derosal Plus e Maxim $\mathrm{XL}$ ), e inoculadas, com ou sem aditivo celular, constituindo dez tratamentos. A sobrevivência das bactérias foi avaliada em quatro períodos pós-inoculação (4, 24, 48 e 72 horas). Os dados foram analisados estatisticamente através da comparação entre as médias dos tratamentos pela técnica de Análise de Variância (ANOVA) e teste de comparações múltiplas de médias (Teste de Tukey). Para, ambas as análises, foi estabelecido o nível de significância de $5 \%$. Os resultados demonstraram que o número de células de bradirrizóbio foi menor nos tratamentos que não receberam aditivo. $\mathrm{O}$ aditivo celular não demonstrou efeito na manutenção da sobrevivência dos microrganismos quando utilizado com os fungicidas Vitavax-Thiram e Derosal Plus, que se apresentaram como os mais prejudiciais aos bradirrizóbios. Os tratamentos que receberam os fungicidas Protreat e Maxim XL foram os que melhor responderam à utilização do aditivo celular. Mais estudos são necessários para um maior esclarecimento acerca da eficácia do produto.

Palavras-Chave: Inoculante, aditivo celular, fungicida, bradirrizóbio.

\begin{abstract}
The modern agricultural techniques application has an important role in the maintaining the level of second largest producer and exporter of soybean reached by Brazil. Among this techniques are highlighted the Bradyrhizobium inoculation and seed treatment with fungicides. Studies have shown incompatibility between inoculated bacteria with other practices of seed treatment. For this reason, industries have developed cell additives, which favor the survival of microorganisms, even in the presence of fungicides. This study aims to evaluate the effect of a cell additive in the Bradyrhizobium survival in inoculated and treated with fungicides soybean seeds. The essay was conducted in 2008 , in the Microbiological Agriculture Laboratory (MIA), located in FEPAGRO, Porto Alegre, southern Brazil. Soybean seeds were treated with four commercial fungicides (Protreat, Vitavax-Thiram, Derosal Plus e Maxim XL), and inoculated, with or without cell additive, constituting ten treatments. The bacteria survival was evaluate in four times (4, 24, 48 and 72 hours). Data were statistically analyzed by comparing the means of treatments by the technique of Analysis of Variance (ANOVA). For both tests, it was established the significance level of $5 \%$. The results showed that the number of Bradyrhizobium cells was lower in treatments without cell additive. The cell additive showed no effect in the survival maintenance of microorganisms when used with Vitavax-Thiram and Derosal Plus fungicides. They were the most harmful to Bradyrhizobium. Treatments with Protreat and Maxim XL were who best responded to the use of cell additive. More studies are needed for further clarification about the effectiveness of cell additive.
\end{abstract}

Keywords: Inoculant, cell additive, fungicide, bradirrizóbi.

\title{
INTRODUÇÃO
}

O interesse mundial na soja (Glycine max) é, em grande parte, devido ao elevado teor de proteína de seus grãos (cerca de $40 \%$ ), constituindo uma importante fonte de alimentação tanto animal, quanto humana (Crispino et al., 2001). A sustentação do patamar de segundo maior produtor e exportador de soja do mundo tem sido mantido pelo Brasil através do aumento progressivo das áreas de cultivo, e também pela elevação da produtividade das lavouras. Como fatores determinantes para isto são apontados, principalmente a indexação do valor da oleaginosa e a aplicação intensiva de técnicas agrícolas modernas. Dentre essas técnicas, as práticas 
fitossanitárias e nutricionais vêm tendo papel preponderante para o atual quadro de participação da soja no mercado internacional.

Desde o advento do plantio direto na cultura desse grão, as práticas fitossanitárias têm evoluído no sentido da diminuição dos riscos e do aumento do retorno econômico, obtidos através de um padrão de lavoura que busque expressar o potencial genético de produção da soja. Dentre essas, destacam-se a aplicação do inoculante, o tratamento de sementes com fungicidas, e a adubação de micronutrientes via semente. Atualmente, as sementes de soja veiculam estes três produtos concomitantemente. No entanto, certos estudos têm demonstrado incompatibilidade entre os bradirrizóbios inoculados e as práticas de tratamento de sementes (Bueno et al., 2001; Campo \& Hungria, 1999; Guene et al., 2003; KyeiBoahen et al., 2001; Oliveira et al., 1999).

Em função disto, surgiu a demanda, por parte das indústrias fabricantes, de testar a aplicação conjunta de fungicidas com inoculantes nas sementes de soja, a fim de verificar a sobrevivência do microrganismo e a viabilidade desta prática sem prejuízo à Fixação Biológica do Nitrogênio (FBN). As pesquisas também foram direcionadas para a busca de formulações de produtos, chamados aditivos celulares, que possibilitam maior concentração de microrganismos vivos nas sementes.

Este estudo se propõe a avaliar um aditivo celular em relação à sobrevivência dos bradirrizóbios nas práticas de tratamento de sementes com fungicidas e aplicação conjunta de inoculante, tendo em vista que tais práticas são plenamente adotadas e podem ter interferência na formação de nódulos e no rendimento da cultura.

\section{MATERIAL E MÉTODOS}

O ensaio foi realizado no ano de 2008, no Laboratório de Fixação Biológica do Nitrogênio (LFBN), pertencente à Fundação Estadual de Pesquisa Agropecuária (FEPAGRO), Porto Alegre, RS.

Sementes de soja da variedade RS10 foram tratadas com quatro fungicidas comerciais - Protreat [PT] (Carbendazim 15\% e Thiram 35\%), Vitavax-Thiram [VT] (Carboxim 20\% e Thiram 20\%), Derosal Plus [DP] (Carbendazim 15\% e Thiram $35 \%$ ) e Maxim XL [MXL] (Fludioxonil 2,5\% e Metalaxyl-M 1\%) -, e aplicadas com inoculante comercial (IC), com e sem aditivo celular (AC). O IC é constituído das 
estirpes SEMIA 5079 (Bradyrhizobium japonicum) e SEMIA 5019 (Bradyrhizobium elkanii). Foram estipulados os seguintes tratamentos:

T1 (Testemunha): sementes com aplicação de IC;

T2 (Tratamento 2): sementes com aplicação de IC e AC;

T3 (Tratamento 3): sementes tratadas com fungicida PT e com aplicação de IC;

T4 (Tratamento 4): sementes tratadas com fungicida PT, com aplicação de IC e adicionado de AC;

T5 (Tratamento 5): sementes tratadas com fungicida VT e com aplicação de IC;

T6 (Tratamento 6): sementes tratadas com fungicida VT, com aplicação de IC e adicionado de AC;

T7 (Tratamento 7): sementes tratadas com fungicida DP e com aplicação de IC;

T8 (Tratamento 8): sementes tratadas com fungicida DP, com aplicação de IC e adicionado de AC;

T9 (Tratamento 9): sementes tratadas com fungicida MXL e com aplicação de IC;

T10 (Tratamento 10): sementes tratadas com fungicida MXL, com aplicação de IC e adicionado de AC.

\section{Análise do ensaio}

A sobrevivência do microrganismo nas sementes foi analisada em quatro períodos de tempo após a aplicação dos produtos nas sementes: 4, 24, 48 e 72 horas. Para cada tratamento foram executadas três análises da sobrevivência da bactéria ( $A, B$ e $C)$, em cada um dos períodos de tempo, totalizando 120 análises. $A$ metodologia de análise da recuperação das bactérias nas sementes baseou-se em diluições decimais seriadas e contagem em placas (método do espalhamento). A análise estatística dos dados foi feita a partir de banco de dados construído em planilha eletrônica Excel. Para a comparação entre as médias dos tratamentos, procedeu-se a Análise de Variância (ANOVA). A análise comparativa entre as médias de sobrevivência entre tratamentos, tomados dois a dois, foi feita através do Teste de Tukey. Todas as análises foram feitas no programa ASSISTAT $^{\circledR}$, e o nível de significância adotado foi o de 5\%. 


\section{RESULTADOS}

O tratamento que recebeu o fungicida PT e AC $\left(\mathrm{T}_{4}\right)$ apresentou melhor sobrevivência dos bradirrizóbios, estatisticamente superior em relação ao respectivo tratamento sem $A C\left(T_{3}\right)$ em todos os períodos de tempo analisados. As sementes tratadas com o fungicida $M X L\left(T_{9}\right)$ obtiveram melhores resultados de sobrevivência da bactéria quando acrescentado o $A C$ ( $\left.T_{10}\right)$ em todos os períodos de tempo, sendo tais resultados estatisticamente significativos a partir das 24 horas (Tabela 1). Já os tratamentos que receberam os fungicidas VT e DP ( $T_{5}$ e $T_{7}$, respectivamente) não demonstraram melhoria significativa na recuperação do microrganismo quando adicionados de $A C$ ( $T_{6}$ e $T_{8}$, respectivamente). Com estes dois últimos fungicidas foram obtidos os resultados mais baixos de recuperação de bradirrizóbios (Tabela 1). Foi constatada uma diminuição no número de células viáveis de bradirrizóbio ao longo do tempo.

Tabela 1. Média do número de UFC por semente de soja em sementes apenas inoculadas, com e sem aditivo ( $\mathrm{T} 1 \mathrm{e}$ T2), e em sementes tratadas com os fungicidas Protreat (PT), Vitavax-Thiram (VT), Derosal Plus (DP) ou Maxim XL (MXL), com e sem aditivo celular (AC) [T2 a T10], nos quatro períodos de tempo avaliados.

\begin{tabular}{|c|c|c|c|c|}
\hline Tratamento & Média 4h & Média 24h & Média 48h & Média 72h \\
\hline T1 Testemunha & $5,47 \times 10^{5} \mathrm{bc}^{(1)}$ & $3,99 \times 10^{5} \mathrm{~cd}$ & $2,33 \times 10^{5} \mathrm{~b}$ & $1,74 \times 10^{5} \mathrm{~b}$ \\
\hline $\mathrm{T} 2 \mathrm{IC}+\mathrm{AC}$ & $5,09 \times 10^{5} \mathrm{C}$ & $6,99 \times 10^{5} \mathrm{a}$ & $4,57 \times 10^{5} \mathrm{a}$ & $3,44 \times 10^{5} a$ \\
\hline T3 PT + IC & $1,01 \times 10^{5} \mathrm{~d}$ & $5,09 \times 10^{4} \mathrm{e}$ & $2,83 \times 10^{4} d$ & $1,10 \times 10^{4} \mathrm{c}$ \\
\hline $\mathrm{T} 4 \mathrm{PT}+\mathrm{IC}+\mathrm{AC}$ & $7,15 \times 10^{5} a$ & $5,97 \times 10^{5} \mathrm{ab}$ & $4,89 \times 10^{5} a$ & $3,29 \times 10^{5} a$ \\
\hline T5 VT + IC & $6,70 \times 10^{4} \mathrm{~d}$ & $5,95 \times 10^{4} \mathrm{e}$ & $3,73 \times 10^{4} \mathrm{~cd}$ & $9,93 \times 10^{3} \mathrm{c}$ \\
\hline $\mathrm{T} 6 \mathrm{VT}+\mathrm{IC}+\mathrm{AC}$ & $1,22 \times 10^{5} \mathrm{~d}$ & $1,15 \times 10^{5} \mathrm{e}$ & $1,09 \times 10^{5} \mathrm{bcd}$ & $6,59 \times 10^{4} b c$ \\
\hline T7 DP + IC & $9,14 \times 10^{4} \mathrm{~d}$ & $4,23 \times 10^{4} \mathrm{e}$ & $1,44 \times 10^{4} d$ & $8,93 \times 10^{3} \mathrm{c}$ \\
\hline $\mathrm{T} 8 \mathrm{DP}+\mathrm{IC}+\mathrm{AC}$ & $1,26 \times 10^{5} \mathrm{~d}$ & $9,51 \times 10^{4} \mathrm{e}$ & $5,56 \times 10^{4} \mathrm{~cd}$ & $4,77 \times 10^{4} b c$ \\
\hline T9 MXL + IC & $6,61 \times 10^{5} \mathrm{ab}$ & $2,71 \times 10^{5}$ & $1,78 \times 10^{5} \quad b c$ & $1,06 \times 10^{5} \quad b c$ \\
\hline $\mathrm{T} 10 \mathrm{MXL}+\mathrm{IC}+\mathrm{AC}$ & $7,35 \times 10^{5} \mathrm{a}$ & $4,84 \times 10^{5} \quad b c$ & $5,00 \times 10^{5} a$ & $3,29 \times 10^{5} a$ \\
\hline
\end{tabular}

(1) Médias seguidas pela mesma letra, na coluna, não diferem estatisticamente entre si pelo Teste de Tukey a 5\%. 
UFC $=$ Unidades Formadoras de Cultura

\section{DISCUSSÃO}

Analisando os resultados dos testes de comparação entre as médias de sobrevivência da bactéria nas sementes, pôde-se evidenciar que o fungicida VT agiu de forma deletéria, diminuindo o número de microrganismos nas sementes, mesmo nos tratamentos que receberam o aditivo celular. Esse mesmo efeito também foi evidenciado nos tratamentos que receberam o fungicida DP. Bueno e colaboradores em 2003 testaram o efeito de fungicidas na sobrevivência e nodulação de Bradyrhizobium japonicum (SEMIA 5019 e SEMIA 5079), e obtiveram resultados in vitro que demonstraram um efeito negativo altamente significativo das combinações de fungicidas Carboxim + Thiram (mesma formulação do fungicida VT). Neste mesmo sentido, Campo \& Hungria em 1999 trabalhando com misturas de fungicidas, encontraram uma redução de $64 \%$ e 57\% de microrganismos, 2 horas e 24 horas após a aplicação dos tratamentos, respectivamente, para Carbendazim + Thiram (mesma formulação do fungicida DP).

Os outros dois fungicidas utilizados nos ensaios (PT e MXL) responderam de maneira mais positiva à utilização do aditivo celular e, de maneira geral, mostraramse menos prejudiciais aos bradirrizóbios do que os demais fungicidas utilizados. Isso talvez se deva às formulações desses produtos, que quiçá possam ser menos tóxicas para o microrganismo. Além disso, o fungicida PT é produzido pela mesma indústria fabricante do aditivo celular e do inoculante utilizado no ensaio, o que também pode explicar a maior compatibilidade entre este fungicida, o aditivo e 0 inoculante.

Outro resultado evidenciado após a análise dos dados foi a diminuição progressiva da quantidade de microrganismos nas sementes em relação ao período de tempo no qual as análises eram realizadas. Tedesco \& Campos em 2000, recomendam que sementes de soja inoculadas não devam ser armazenadas por mais de um dia, para que o patamar sugerido de células viáveis de bradirrizóbio por semente seja alcançado. Atualmente, a pesquisa está recomendando a concentração de 1.200.000 células de bradirrizóbio por semente de soja, devido à alta taxa de mortalidade causada por fungicidas e outras causas, com o intuito de garantir a 
sobrevivência de um número razoável de bactérias nas sementes, resultando na infecção e nodulação eficiente da soja (Campo et al., 2008).

Sabe-se que várias empresas fabricantes de inoculantes vêm desenvolvendo trabalhos testando formulações aditivas para utilização conjunta com inoculantes, fungicidas e/ou micronutrientes, mas não possuem estes trabalhos publicados. Desse modo há ausência de literatura científica sobre o assunto, o que não permite estudos de comparação entre o comportamento das formulações no sentido de proteção do microrganismo. Entretanto, os dados de recuperação das bactérias nas sementes validam o emprego do aditivo celular para a sobrevivência da bactéria nas sementes juntamente com a utilização dos fungicidas PT e MXL.

\section{CONSIDERAÇÕES FINAIS}

1. A utilização do aditivo celular nas práticas de inoculação junto com o tratamento de sementes de soja com os fungicidas PT e MXL garante melhorias na sobrevivência e longevidade dos bradirrizóbios na semente.

2. O aditivo celular mostrou esse mesmo benefício quando utilizado apenas no processo de inoculação.

3. De acordo com os resultados obtidos neste estudo, indicamos a recomendação do aditivo celular para a utilização conjunta com inoculante e fungicida PT no tratamento de sementes de soja, com o objetivo de melhorar a sobrevivência e longevidade dos bradirrizóbios nas sementes, e maximizar a tecnologia da Fixação Biológica do Nitrogênio. A mesma recomendação é válida para o fungicida MXL.

\section{AGRADECIMENTOS}

À empresa Merck Crop Bioscience, pela doação dos insumos e patrocínio do ensaio.

\section{REFERÊNCIAS}


BUENO, C.J.; MEYER, M.C.; SOUZA, N.L. Efeito de fungicidas na sobrevivência de Bradyrhizobium japonicum (SEMIA 5019 e SEMIA 5079) e na nodulação de soja. Acta Scient.: Agron. 25: 231-235, 2003. 
CAMPO, R.J.; ARAÚJO, R.S.; MOSTASSO, F.L.; HUNGRIA, M. EFEITO DA POPULAÇÃO DE CÉLULAS NA NODULAÇÃO E RENDIMENTO DA SOJA. IN: REUNIÃO DE PESQUISA DE SOJA dA REGIÃO CENTRAL DO BRASIL, 30., RıO VERDE, 2008. RESUMOS. LONDRINA, EMBRAPA SOJA, 2008. P. 302-304.

CAMPO, R.J.; HUNGRIA, M. EFEITO dO TRATAMENTO DE SEMENTES DE SOJA COM FUNGICIDAS NA NODULAÇÃO E FIXAÇÃO SIMBIÓtICA DO N2. LONDRINA, 1999. EMBRAPA SOJA:PESQUISA EM ANDAMENTO. 7P.

CRISPINO, C.C.; FRANCHINI, J.C.; MORAES, J.Z.; SIBALDELLE, R.N.R.; LOUREIRO, M.F.; SANTOS, E.N.; CAMPO, R.J.; HUNGRIA, M. 2001. ADUBAÇÃO NITROGENADA NA CULTURA DE SOJA. LONDRINA. EMBRAPA SOJA: COM. TÉc.75: 6P, 2001.

GUENE, N.F.D.; DIOUF, A. GUEYE, M. NODULATION AND NITROGEN FIXATION OF FIELD GROW COMMOM BEAN (PHASEOLUS VULGARIS) AS INFLUENCED BY FUNGICIDE SEED TREATMENT. AFRIC. JOURN. OF BIOT. 2:198-201, 2003.

KYEI-BOAHEN, S.; SLINKARD, A.E.; WALLEY, F.L. RHIZOBIAL SURVIVAL AND NODULATION OF CHICKPEA AS INFLUENCED BY FUNGICIDE SEED TREATMENT. CANAD. JOURN. OF MICROB. 47:585-589, 2001.

OLIVEIRA, P.P.A.; TSAI, S.M.; CORSI, M.; DÍAZ, M.D.P. INTERAÇÃO ENTRE CULTIVARES, ESTIRPES COMERCIAIS DE RHIZOBIUM MELILOTIE FUNGICIDAS NO INCREMENTO da PROdução de alfafa. Pesq. Agropec. Bras. 34:425-431, 1999.

TEDESCO, V.; CAMPOS, B.C. SobreVIVÊNCIA DE CÉLULAS DE BRADYRHIZOBIUM NA SUPERFíCIE de SEMENTES DE SOJA. ReV. CIENT. UnICRUZ. 3:9-15, 2000. 